\title{
Cultivar Registration at the Arnold Arboretum 1994
}

\author{
Stephen A. Spongberg ${ }^{1}$ \\ The Arnold Arboretum of Harvard University, 125 The Arborway, Jamaica Plain, MA 02130, USA
}

The Arnold Arboretum of Harvard Univ. continues to serve as International Registration Authority for cultivar names in 11 genera of ornamental woody plants, and the following notes pertain to cultivar names that have been registered at the Arboretum since the last list was prepared. The 11 genera include Chaenomeles, Cornus, Fagus, Forsythia, Gleditsia, Lantana, Malus (ornamental species), Philadelphus, Pieris, Ulmus, and Weigela. Inquiries concerning the registration of cultivar names in these genera should continue to be addressed to S.A. Spongberg, The Arnold Arboretum, The Arborway, Jamaica Plain, MA 02130 USA.

Two new cultivar names were registered during the past year, one in Malus and one in Ulmus.

Malus pumila Miller 'Pink Joy'. Registered 26 May 1994. Registrant: Norman Stewart, Lockstead Settlement, Box 69, Blackville, New Brunswick E0C 1C0, Canada. Malus 'Pink Joy' has been selected and named by Norman Stewart. First observed 1978, 'Pink Joy' is a

${ }^{1}$ Horticultural Taxonomist. chance seedling that produces variegated flowers in which the petals are pink and white, with the lower surfaces more pink than the upper ones. In other characteristics, 'Pink Joy' is similar to other individuals of the species.

Ulmus davidiana var. japonica (Rehd.) Nakai 'Discovery'. Registered 16 Aug. 1994. Registrant: Rick Durand, Prairie Shade Nursery, 89 Wilkinson Crescent, Portage la Prairie, Manitoba R1N 1A7, Canada. Rick Durand originated and introduced Ulmus davidiana var.japonica 'Discovery'; it was selected in 1985 from open-pollinated seedlings grown from seeds collected from 20 mature Japanese elms at the Morden Research Station. 'Discovery' originally was referred to under number 8502 and has been selected and named because of its distinct habit. Compared to the vase-like habit of most Japanese elms, 'Discovery' has a distinctly upright, more compact, vase-like habit, and its leaves are $10 \%$ smaller than those of 'Freedom' and 'Jacan'. It also is believed that 'Discovery' will prove hardy into U.S. Dept. of Agriculture hardiness zone $2 \mathrm{~b}$. 